\title{
Embedding science and innovation in forest management: Recent experiences at Millar Western in west-central Alberta
}

\author{
by Laird Van Damme ${ }^{1}$, Peter N. Duinker² and Dennis Quintilio ${ }^{3}$
}

\begin{abstract}
Research from scientists embedded within Millar Western's forest management planning process over the last 14 years was enabled by strong corporate leadership, cooperation by Alberta's Ministry of Sustainable Resource Development, and funding by the Forest Resource Improvement Association of Alberta. Results of the supporting research are described in the articles that follow and are important contributions to Canada's commitment to sustainable forest management (SFM). The process is as noteworthy as the results and is the subject of this paper. When scientists and practitioners work closely together in developing a forest management plan, as they have in this case, there is a much greater opportunity for science-based emergent strategies to be created and applied through the personal interactions among scientists and practitioners. For example, input from the science-based collaborators influenced the harvest schedule in the detailed forest management plan to minimize negative effects on water flow, biodiversity and fire risk. This approach to SFM is one of many being developed in Alberta. The diversity of input has clear benefits, not the least of which is the maintenance of innovation and intellectual enterprise in support of SFM.
\end{abstract}

Key words: forest management planning, forest science, innovation, Alberta, biodiversity, timber supply, guidelines

\section{RÉSUMÉ}

Les travaux de recherche inclus par les chercheurs dans le processus de planification forestière de Millar Western au cours des 14 dernières années ont été réalisés grâce au leadership soutenu de l’entreprise, la coopération du ministère du Sustainable Resource Development de l'Alberta et le financement assuré par le Forest Resource Improvement Association de l'Alberta. Les résultats des travaux entrepris sont décrits dans les articles qui suivent et constituent une contribution importante à lengagement du Canada en matière d’aménagement forestier durable (AFD). Le processus autant que les résultats sont remarquables et font lobjet de cet article. Lorsque les chercheurs et les praticiens travaillent en étroite collaboration au développement d'un plan d'aménagement forestier, comme dans ce cas, il y a une plus grande possibilité de voir émerger des stratégies reposant sur des bases scientifiques et qu’elles soient appliquées suite aux interactions personnelles entre les chercheurs et les praticiens. À titre d'exemple, les intrants fournis par les collaborateurs scientifiques ont eu une influence sur le programme de coupe du plan détaillé d’aménagement forestier élaboré pour minimiser les effets négatifs sur l'écoulement des eaux, la biodiversité et le risque de feux de forêt. Cette approche d'AFD est l'une des nombreuses en voie de développement en Alberta. La diversité des intrants engendre des bénéfices évidents, l’un d’eux et non le moindre étant le maintien de l'innovation et de la recherche intellectuelle se rapportant à l’AFD.

Mots clés : aménagement forestier durable, planification de l’aménagement, sciences forestières, innovation, Alberta, biodiversité, approvisionnement en matière ligneuse, directives

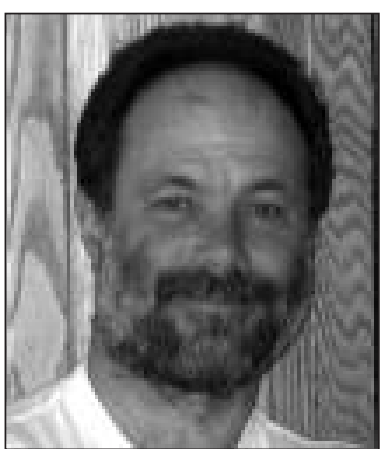

Laird Van Damme

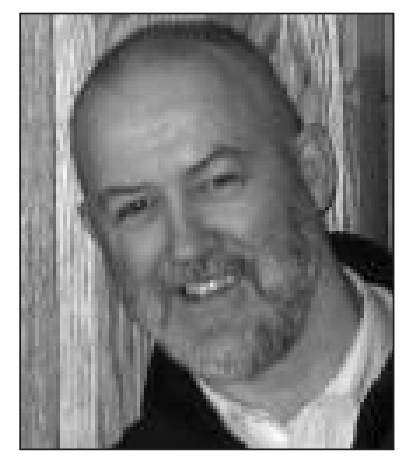

Peter N. Duinker

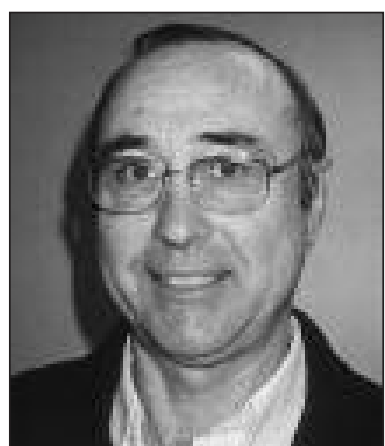

Dennis Quintilio

\footnotetext{
${ }_{1}^{1}$ KBM Forestry Consultants Inc., 349 Mooney Avenue, Thunder Bay, Ontario P7B 5L5. E-mail: vandamme@kbm.on.ca

${ }^{2}$ School for Resource and Environmental Studies, Dalhousie University, 6100 University Avenue, Halifax, Nova Scotia B3H 3J5. E-mail: peter.duinker@dal.ca

${ }^{3}$ PO Box 345 Glenevis, Alberta T0E 0X0. E-mail: dquin@telusplanet.net
} 


\section{Introduction}

The collection of articles on the scientific and technical advances in support of Millar Western Forest Products Ltd.'s Detailed Forest Management Plan (DFMP) in this issue of The Forestry Chronicle provides a unique contribution to the growing body of knowledge in support of Canada's commitment to sustainable forest management (SFM). The most recent DFMP describes the proposed activities for the period covering 2007 to 2016.

Thematic content of the 2007-2016 DFMP is readily referenced to the Canadian Council of Forest Minister's (CCFM) criteria of SFM (CCFM 2003). Many of the indicators for each criterion were developed by several of the impact assessment groups (IAGs) working on plan development. A portion of this support work is featured in the accompanying articles.

Millar Western's first DFMP covered the period of 1997-2006 and began with the signing of a Forest Management Agreement (FMA) in 1996. However, the plan itself was not submitted until 2000. The work featured in this collection of articles focuses upon the most recent DFMP, but much of the foundation was laid in 1994 in preparation of the first DFMP submission.

We have been involved in the development of both plans, providing input as regulator (Dennis Quintilio), forester (Laird Van Damme) and scientist (Peter Duinker), in the first DFMP and as peer-review coordinators in the most recent DFMP. This unique perspective, combined with our experiences in other jurisdictions, allows us to make several observations.

The quality of research and due diligence embodied in both the DFMP and supporting work reflects a high standard. Indeed, several aspects related to hydrology, demographics, climate change, biodiversity conservation, and cumulative effects assessment of other land uses such as oil and gas development are ground-breaking. Several factors contributed to this advance and are described below.

\section{Leadership}

Millar Western is a family-owned corporation that started three generations ago in Whitecourt, Alberta. Today the company operates a pulp mill and sawmill in Whitecourt with sawmills in Fox Creek and Boyle that, in total, employ 600 people. The company is registered under CSA Z809 and ISO 14001 and is guided by a strong environmental policy. Its forest policy states: "Millar Western is committed to sustaining healthy, biodiverse forests for the future, balancing environmental, social, and economic needs while supplying the timber requirements of our manufacturing operations." ${ }^{4}$

The Millar family shows leadership through direct involvement in all aspects of the business including development of both DFMPs. This leadership created a corporate culture that places high values on family, productivity, innovation, integrity and social responsibility. The forest management program at Millar Western is led by a visionary staff consisting of professionals who are highly dedicated, practical and business-minded. Most importantly, their efforts in advancing the practice of SFM receive strong support from Millar Western's owners in a consistent manner with a view toward setting and meeting long-term goals.

\footnotetext{
$\overline{{ }^{4} \text { Millar Western Web site (http://www.millarwestern.com/forest.php) }}$
}

\section{Governance}

Most of Alberta's forests are situated over the Western Sedimentary Basin which provides $50 \%$ and $75 \%$ of Canada's oil and natural gas, respectively. This presents a unique combination of overlapping resource tenures and poses significant integrated land management challenges in addition to the complex forest management obligations, which include the incorporation of wildfire risk. Millar Western has willingly embraced these challenges through innovative, science-based planning approaches that are adapted to one of the busiest forest landscapes in Canada.

Alberta's forest regulations are not overly prescriptive compared to other jurisdictions and the planning standard for the province is based upon CSA Z809, the most widely used forest certification standard in Canada. Although not all plans in Alberta would match the level of detail and scientific rigour of Millar Western's DFMP, many plans are as progressive while several are less so. Highly prescriptive regulations as found in other jurisdictions may lead to more consistent outcomes but this may come at the expense of innovation.

Alberta's Ministry of Sustainable Resource Development (SRD), like most public land-management agencies in Canada, has dedicated professional staff. These individuals played critical roles in enabling Millar Western to advance its interpretation and application of SFM. Other jurisdictions have similar civil services and dedicated professionals but their regulatory regimes lead them to operate more as unintentional "gate-keepers" rather than enablers of innovation in SFM.

The leadership of both Millar Western and SRD made it clear that they were willing to adjust forest management practices in light of scientific advances made by the support groups engaged by Millar Western. This openness to accept new ideas strongly motivated the support groups and played a critical role in the dynamics described below.

\section{Funding}

Funding for much of the research and development supporting Millar Western's DFMP was obtained through The Forest Resources Improvement Association of Alberta (FRIAA). ${ }^{5}$ FRIAA was established in 1997 as a non-profit society as defined by the Societies Act of Alberta. It was created under the Forest Resources Improvement Regulation (OC 354/97) pursuant to the Forests Act and the Environmental Protection and Enhancement Act (Section 12a). The regulation extends Ministerial powers to the Association to administer programs and initiatives for the purposes of:

a) enhancement of forest resources;

b) promotion of enhanced management of the forest resources;

c) improvement of sustained yield of the forest resources; and,

d) promotion of integrated resource management.

Most Association members are tenure holders but there is an allowance for honorary (non-voting) members. Funds for the Association are generated by dues collected from its members indexed with Crown dues for harvested wood. The Association can accept donations and charge fees for its services, but these funds are incidental compared to those derived 
from dues. Day-to-day management is contracted by the Board of Directors to a consulting firm. Members submit outlines for proposals to the firm to finance projects consistent with FRIAA's goals. Once approved for funding in principle, the member submits a detailed work plan that requires approval of the Board of Directors.

Similar funding bodies exist in other jurisdictions, such as the Forest Investment Account in British Columbia and Forestry Futures Trust in Ontario. However, they have a narrower mandate and less local control over how funds are allocated. FRIAA was able to finance support work for Millar Western's DFMP because of FRIAA's unique structure and expansive mandate. We believe that this kind of funding control, kept at arm's length from the member licensees and the government, is a critical success factor.

\section{Commitment to Staying the Course}

The long-term view held by Millar Western's management is a key ingredient in the approach to research in support of SFM. For example, the origins of the Biodiversity IAG (Doyon and Duinker 2003) preceded the development of the 1997-2006 DFMP at the conceptual stage in 1994. This stage is represented by B0 in Fig. 1 and is part of a set of analytical tools referred to as BAPTools (where BAP stands for Biodiversity Assessment Project). The BAPTools helped to screen several competing management strategies in the 1997-2006 DFMP that was submitted in 2000 (B1) (Fig. 1) (Van Damme et al. 2003). The plan start period of 1996 coincided with the FMA start date and a draft plan was to be submitted within three years, but the actual time from conceptualization (B0) to application (B1) was six years. At that time (B1), the biodiversity assessment completed by Millar Western in support of its DFMP (Doyon and Duinker 2003) was cutting-edge in terms of scientific advancement and addressing an important public-policy concern.

A de-briefing meeting of the IAGs for the 1997-2006 DFMP development was held in October 2000. Although the accomplishments for B1 were significant and well beyond industry standards, Millar Western and the developers had hoped for better integration and utility of the BAPTools in the next planning process. There was a desire to "squeeze the lemon" harder to gain further insight from the analytical power of BAPTools and to better integrate biodiversity conservation principles with forest management planning.

Millar Western retained the key individuals from the 1997-2006 DFMP to participate in the 2007-2016 DFMP Biodiversity IAG. This has allowed insights from B1 to be applied in the development of the 2007-2016 DFMP (B2) (Fig. 1) with biodiversity conservation principles being more fully integrated into the forest management planning process. Thus, the time from conceptualization to full application (B0 to B2) has exceeded a decade.

The Landscape Planning Group (LPG) was responsible for assessing cumulative effects of climate and demographic change combined with oil and gas development, and evolved at a similar rate and pattern as the Biodiversity IAG. Its conceptualization stage (L0) emerged in 1999 and was articulated in the preface to the 1997-2006 DFMP (L1) (Fig. 1). Cumulative effects assessment was a new policy concern in the early part of this decade (and century), as was biodiversity in the early 1990s. With the continual escalation of oil and gas land sales and exploration in Alberta, cumulative effects are more

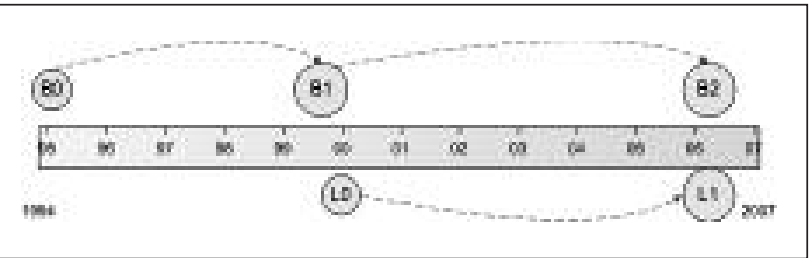

Fig. 1. Timeline for the development stages of the Biodiversity IAG (BO to B2) and the Landscape Planning Group (LO to L1).

of a burden on the forest industry as information from exploration drives oil and gas development rather than land-use planning. At the end of the day, the reality of incorporating the surface disturbance of the petroleum industries sub-surface resource can only be addressed in forest management plans.

The development of analytical tools to deal with the problem of cumulative effects of land-use patterns of both the petroleum and forest industries poses similar challenges faced by Millar Western compared to when BAPTools were developed. The company is commended for staying the course in its investments that advance forest science, forest policy, forest management and integrated resource management. If there is a disappointment in the whole enterprise of biodiversity assessment on Millar Western's leased timber landbase, it is the ongoing inability of the company and its associates to entice other major industrial users of the landbase (e.g., the oil and gas industry) to become full partners in biodiversity assessment using models such as those embodied in BAPTools.

\section{Embeddedness}

Experiences from other jurisdictions show that the development times from concept to application (e.g., B0 to B2) are similar, if not longer, compared to the development times of Millar Western. Although the development times are similar in other settings, the impacts on forest management are often less immediate. We believe that the effectiveness of Millar Western's program is greater than most other initiatives with which we are familiar due to the mutual embedding of scientists in the planning process and managers in the research and development $(\mathrm{R} \& \mathrm{D})$ process.

When scientists and practitioners work closely together in developing a forest management plan, as they have in this case, there is a much greater opportunity for science-based emergent strategies to be created and applied through the personal interaction between scientists and practitioners. For example, input from the science-based collaborators influenced the harvest schedule in the DFMP to minimize negative effects on water flow, biodiversity and fire risk. We call the Millar Western model of science and practitioner interaction "embeddedness."

In other settings, scientists work in relative isolation either in academia or government institutions. There is a risk in the latter situation of research being unduly influenced by government priorities and policies. In some jurisdictions, applied scientists' work is often used to develop management guidelines. Practitioners are more likely to accept guidelines they have co-developed with scientists, as is the case with Millar Western, compared to guidelines developed by government 
research groups, such as the marten habitat guidelines in Ontario (Watt et al. 1996). In addition, the guidelines are inherently more practical if practitioners are involved. Practitioners also gain a deeper understanding of the rationale for changing practices if those changes are shown to be needed.

Embedding science within management planning requires some compromises. The development of BAPTools began with relatively high theoretical science value and relatively high forest management utility value (B0 and B1) (Fig. 2). These value scores would be lower than purely theoretical science ventures in terms of science value, but at the cost of management utility.

The pull between management value, represented by the Timber Supply Analysis (TSA) group in the Millar Western DFMP process (T1 in the 1997-2006 DFMP and T2 in the 2007-2016 DFMP), and the science value of the Biodiversity IAG explains the relative position of these groups ( $\mathrm{T} 1$ and $\mathrm{B} 1$ ) compared to conventional forest management planning groups (M1). The latter operate in isolation of science-based groups (S1) found in most other jurisdictions and planning settings (Fig. 2).

From the conceptual stage (0) to the application (1) and full implementation (2) stages, one sees an increase in management utility value and a further reduction in distance between $\mathrm{T} 2$ and $\mathrm{B} 2$, representing an increase in the science value of the TSA. In addition, there is an increase in empirical science value at stage 2 because data have been collected as part of a monitoring program. As described in both DFMPs, this was done to test key assumptions underlying the analyses of both timber supply and biodiversity conservation.

Since L1 is at a different stage of development, it relies to a larger extent on hypothesis generation (Fig. 2). However, the experience from the Biodiversity IAG at B2 provides positive feedback to the LPG at the L1 stage of development. Over time, the LPG will be testing the hypotheses and evolving to a higher plane based upon empirical evidence.

The science and management space occupied by Miller Western along the planes shown in Fig. 2 is relatively unique compared to most other forest-management settings. The arcs of change from B1 to B2, and the influence of $\mathrm{B} 2$ on L1, represent adaptive management at a high level of practice by Millar Western.

Several other IAG or support teams made important contributions to the DFMPs, and they are not depicted in Fig. 2 given the limitations of a conceptual diagram. For example, Canadian Forest Service scientists helped develop landscape design approaches that were "firesmart" and considered integrated pest management (e.g., Hirsch et al. 2001). There were also important contributions in forest climatology, hydrology, sociology and economics disciplines (e.g., Smith et al. 2003). In all, about 60 specialists were engaged in support functions associated with the two plans. Some logistical challenges had to be overcome by Millar Western managers. Arms-length management of free-thinking scientists is akin to herding cats, creating a unique challenge that was overcome by Millar Western.

The conceptual ordination in Fig. 2 manifested itself in real life through strenuous debates among the various support groups and the lead planners. There was considerable creative tension, which became a necessary part of the process. The planning process at times became delayed,

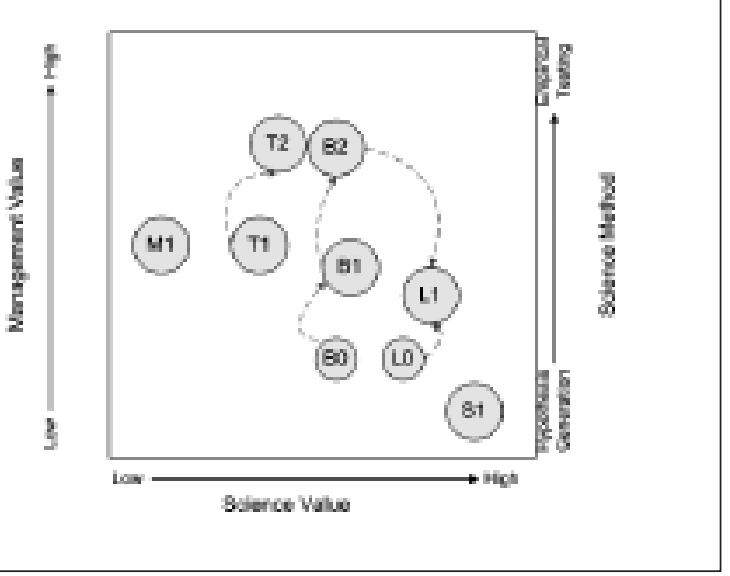

Fig. 2. Conceptual model of different science value, methods and management value.

bogged down by the necessary due diligence of the work by embedded scientists.

The leadership qualities of Millar Western management staff ensured that creative tension did not degenerate into acrimony or other forms of disruption. In fact, our experience through this process was most positive and we witnessed a productive cross-pollination of ideas between managers and scientists. The process led to improvements in the work of both groups, and built long-lasting friendships with thoroughly good (and occasionally stressful) times experienced by all.

\section{Ownership and Diversity}

Appropriate leadership, governance, and commitment have prompted staff at Millar Western to have a strong sense of ownership of the DFMP. Monitoring programs are thus highly focused. For example, graduate-student research has tested several of the wildlife habitat supply models (HSMs) within BAPTools and this has led to an improved understanding of these species as well as developing highly qualified persons through the education process (e.g., Doucette 2002, Ancelin 2003, Bone 2003, Hautala 2004).

Another advantage of the cooperative approach involving SRD and Millar Western is a provincial policy setting that allows for diversity in approaches to SFM. Other licensees, such as Alberta-Pacific, have developed alternative yet equally sound approaches to SFM. Several groups have come together as part of the Alberta Biodiversity Monitoring Institute (ABMI) to monitor biodiversity effects of land use at the provincial scale. More than 2000 species and habitats are tracked by the ABMI using remote sensing and field-sampling protocols over a grid of 1656 sites distributed evenly throughout the province. ${ }^{6}$

These other initiatives work at different locations and scales than those required for Millar Western to achieve SFM goals on its license area. But there is more than a utility argument for the diverse ways in which various licensees attempt to implement SFM in Alberta. Just as we need to conserve biodiversity to allow ecosystems to adapt to changing envi-

\footnotetext{
${ }^{6}$ Alberta Biodiversity Monitoring Institute Web site (http://www. abmi.ca/abmi/home/home.jsp)
} 
ronments, we must conserve intellectual diversity to allow society to adapt to new environments, be they biophysical as a result of climate change or social as a result of changing trade policies. Millar Western and Alberta's SRD have made an important contribution to the diversity of approaches to SFM in the processes associated with development, approval and implementation of the 2007-2016 DFMP.

\section{Adaptive Management}

Duinker and Trevisan (2003) argued for a return to basics in interpreting the concept of adaptive management. Going back to early definitive treatments of the topic in the context of natural resources and the environment (Holling 1978, Walters 1986), we are led here to reflect on the degree to which forest management at Millar Western is characterized by exemplary implementation of adaptive management. Two domains are relevant: the interactions among scientists and decision-makers/practitioners, and uncertainty reduction through science.

In our view, the embeddedness model of enlightening forest management with scientific knowledge represents the pinnacle of strong interactions among scientists and decisionmakers. Early manifestations of adaptive management involved a series of workshops where key stakeholders interacted with scientists, first in qualitative systems analysis and subsequently in computer-based simulation analysis. Having been involved directly in the interactive development of scientific inquiry in relation to Millar Western's two major forest planning exercises, we assert with confidence that this aspect of adaptive management was implemented to great effect. The company seems to have engaged in quantum leaps forward in organizational learning that, with appropriate codification and ongoing nurture, should pave the way for continued achievement in sustainable forest management.

On the science side, as Lee (1993) noted, it may take decades before outcomes are sufficiently well revealed before confident assessments can be made about the effectiveness of specific management strategies. That principle notwithstanding, we believe that recent/current science initiatives associated with Millar Western's forest management program display adaptive management in progress. First, Millar Western sponsored a series of field tests of specific HSMs (as referenced above) in the BAPTools suite of computerized models, and model recalibration for the latest plan has been accomplished. Second, the permanent sample plot (PSP) program implemented by the company was re-designed to collect additional data associated with models contained in BAPTools. Long-term monitoring protocols for many ecological variables are still being worked out, but it is still early times for the overall science program at Millar Western, and the track record of the company bodes well for expected success in this regard.

\section{Summary and Conclusions}

Millar Western's DFMP process embedded scientists directly within the planning process. The ownership and management of the company encourage innovation. Alberta's SRD enabled the company to pursue a unique approach to SFM as did the funding mechanism administered by FRIAA. The company has taken a long-term view in supporting the work that involved some 60 specialists from across Canada over the past 14 years. The scientists and specialists embedded within the planning process enabled science-based strategies to emerge. The resulting sense of ownership among management staff leads to changes in forest practices and a cohesive monitoring program. The quality of research and due diligence embodied in both the DFMP and supporting work reflects a high standard. Indeed, several aspects related to hydrology, demographics, climate change, biodiversity conservation, and cumulative effects assessment have been ground-breaking.

Millar Western and Alberta's SRD have made an important contribution to the diversity of approaches to SFM in the processes associated with development, approval and implementation of Millar Western's 2007-2016 DFMP. This approach to SFM is one of many being developed in Alberta. The diversity has clear benefits, not the least of which is the support of a rich and diverse intellectual enterprise in support of SFM. The papers that follow summarize the results of a range of projects associated with that intellectual enterprise.

\section{References}

Ancelin, R. 2003. Evaluation of a spatially explicit habitat suitability model applied in west-central Alberta for the least flycatcher. Unpublished Master's Thesis. School for Resource and Environmental Studies, Dalhousie University, Halifax, NS.

Bone, S. 2003. Evaluation of a spatial habitat suitability index model for varied thrush in west-central Alberta. Unpublished Master's Thesis. School for Resource and Environmental Studies, Dalhousie University, Halifax, NS

Canadian Council of Forest Ministers (CCFM). 2003. Defining sustainable forest management in Canada: Criteria and indicators 2003. 23 p. [online] Available at http://www.ccmf.org/ci/CI_Booklet_e.pdf.

Doyon, F. and P.N. Duinker. 2003. Assessing forest-management strategies through the lens of biodiversity: a practical case from central-west Alberta. In G.J. Arthaud and T.M. Barrett (eds.). Systems Analysis in Forest Resources. pp. 207-224. Kluwer Academic Publishers, Dordrecht, the Netherlands.

Doucette, A. 2002. An assessment of a GIS-based habitat suitability index model for Canada lynx in west-central Alberta. Unpublished Master's Thesis. School for Resource and Environmental Studies, Dalhousie University, Halifax, NS.

Duinker, P.N. and L.M. Trevisan. 2003. Adaptive management: progress and prospects for Canadian forests. In V. Adamowicz, P. Burton, C. Messier and D. Smith (eds.). Chapter 21. Towards Sustainable Management of the Boreal Forest: Emulating Nature, Minimizing Impacts and Supporting Communities. pp. 857-892. NRC Press, Ottawa, ON.

Hautala, K. 2004. Evaluation of a spatial habitat supply model for the northern goshawk (Accipiter gentilis) in west-central Alberta. Unpublished Master's Thesis. Lakehead University, Thunder Bay, ON. 100 p.

Hirsch, K., V. Kafka, C. Tymstra, R. McAlpine, B. Hawkes, H. Stegehuis, S. Quintilio, S. Gauthier, and K. Peck. 2001. Firesmart forest management: A pragmatic approach to sustainable forest management in fire-dominated ecosystems. The Forestry Chronicle 77(2): 357-363

Holling, C.S. (ed.). 1978. Adaptive Environmental Assessment and Management. John Wiley and Sons, Toronto, ON. 377 p.

Lee, K.N. 1993. Compass and gyroscope: Integrating Science and Politics for the Environment. Island Press, Washington, DC. 243 p.

Smith, D.W., E.E. Prepas, G. Putz, J.M Burke, W.L Meyer, and I. Whitson. 2003. The Forest Watershed and Riparian Disturbance study: a multi-discipline initiative to evaluate and manage watershed disturbance on the Boreal Plain of Canada. Journal of Environ-mental Engineering and Science. 2 (Suppl. 1): 1-13. 
Van Damme, L., J. Russell, F. Doyon, P. Duinker, T. Gooding, K. Hirsch, R. Rothwell, and A. Rudy. 2003. The development and application of Decision Support Systems for sustainable forest management on the Boreal Plain. Journal of Environment Engineering and Science (2): S23-S34.

Walters, C.J. 1986. Adaptive Management of Renewable Resources. MacMillan Publishing Company, New York, NY. 374 p.
Watt, W.R., J.A. Baker, D.M. Hogg, J.G. McNicol and B.J. Naylor. 1996. Forest management

guidelines for the provision of marten habitat. Version 1.0. Ontario Ministry of Natural Resources, Ottawa, Ontario. MNR\#50908. 24 p. 